\title{
Factors Associated With Student Attrition And Retention In An Educational Leadership Doctoral Program
}

\author{
Michelle Nadine Stallone, (E-mail: mnstallone@ hotmail.com), Texas A \& M University, Kingsville
}

\begin{abstract}
The purpose of the study was to examine the factors behind doctoral student attrition. Findings indicated that doctoral students perceive human factors to be the most significant for program completion.
\end{abstract}

\section{Introduction}

"Half of doctoral students drop out, not because they aren't bright, but because they aren't sophisticated in the ways of academe." --Peggy Hawley, Ph.D., 1993

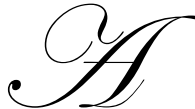

mericans are becoming more educated. Between 1970 and 2000, the proportion of the adult population 25 years of age and over with a bachelor's or higher degree increased from 11 percent to 26 percent (National Center for Education Statistics, 2001). More specifically, the number of adults who have earned doctor's degrees has been steadily increasing over the past 30 years. According to the National Center for Education Statistics (2001), the number of doctor's degrees conferred by colleges and universities during the academic year 2000-01 was estimated to be 46,700. This is a sharp increase since the 1970s when only 32,107 doctor's degrees were conferred.

For the past 40 years, the increase in the number of doctorates awarded by U.S. universities has averaged 3.8 percent per year (Hoffer, Dugoni, Sanderson, Sederstrom, Ghadialy, \& Rocque, 2001). Currently, almost 47,000 adults are earning their doctor's degrees at over 400 universities in the United States (Hoffer, et al., 2001). Overall, more people are attending college to earn not only bachelor's, but also advanced degrees.

As presented in the Survey of Earned Doctorates (SED), the number of doctorates awarded within the six broad fields of study (physical sciences, engineering, life sciences, social sciences, humanities, and education) varies (Hoffer, et al., 2001). Doctorates conferred in the life sciences numbered 8,521, while the broad field of education conferred 6,417 degrees in 2000. Time to degree also varies from field to field, as well as from program to program. The median number of registered years from the baccalaureate to doctorate is 8.1 years for the field of education; second only to the humanities, which average 8.8 years.

The rate of attrition in doctoral programs has been historically high. Approximately 50 percent of all doctoral students in this country fail to complete their programs, and this number has remained constant for the past fifty years (Dorn \& Papalewis, 1997; Lovitts, 1996). Even more alarming is the fact that most of the students who fail to complete the program have finished their coursework for the degree and even have taken their comprehensive examinations (Sigafus, 1998). "Although few students terminate their pursuit of a doctorate during the course-work phase of their program, many doctoral students drop out around the time that they successfully complete planned courses, a period known as 'all but dissertation' (ABD)" (Sigafus, 1998, p. 1).

The formation of doctoral student and faculty cohorts has been a contemporary effort by universities to reduce the occurrence of doctoral program attrition. Doctoral student cohorts have been shown to be somewhat effective in promoting the retention of doctoral students in professional schools (Wesson, Holman, Holman, \& Cox, 
1996). Similarly, doctoral students are more likely to persist in educational programs that rely on the element of peer mentoring (Dorn \& Papalewis, 1997). Still, even with these thoughtful interventions, high attrition rates remain.

Other than number of graduates in each field, what is really known about who persists in college? Who perseveres on the path toward a college degree or credential, while others do not? It has only been in the past six to eight years that a limited amount of quantitative information about doctoral student attrition has become available (Parent, 1999). This has become possible partly because of the increased data analysis and student tracking capabilities of institutions. In addition, there have been a limited number of studies during the past decade that have gathered the kinds of qualitative information that provide greater insight into student perceptions of the doctoral experience (Bair, 1999; Parent, 1999).

Barbara Lovitts (1996) notes how graduate schools have responded to the problem of attrition by placing greater emphasis on selection and assuming that more informed decisions about admission would lessen the rate of attrition. Attrition persists, however, and the question arises as to whether it is more the result of characteristics of individual graduate students or of factors inherent in the structure, process, and culture of graduate education.

Research on doctoral student persistence and attrition is readily available; however, findings only confirm that the decision to persist in or to depart from one's chosen program of doctoral study is a multifaceted and dynamic process. Studies (Bair, 1999; Parent, 1999; Sigafus, 1998) have identified four major areas, or factors, often examined for their relationship to doctoral student retention. These four factors are as follows: (1) academic factors; (2) demographic factors; (3) individual/psychological factors; and (4) human/program cultural factors.

Traditionally, researchers (e.g., Lemp, 1980; Nagi, 1974) have focused on academic factors, including standardized test scores and academic grades, when seeking to understand doctoral degree completion. Another commonly cited explanation has focused on demographic factors, such as student gender, ethnicity, and age (Bowen \& Rudenstine, 1992; Donnelly, 1985). Similarly, researchers (e.g., Bishop, 1981; Tluczek, 1995) have studied individual/psychological factors, such as career goals, financial situation, and motivation of students as the primary explanation of student attrition. Academic, demographic, and individual/psychological factors are all features internal to students, and therefore may not necessarily be within the control of the institution.

More recently, however, researchers have argued that attrition has less to do with what the student brings to the university than with what happens to the student after she or he has been admitted, such as the program structure or culture (Lovitts, 1996). For example, students who do not experience a supportive instructional environment may be more likely to exit the program. The perception is that campuses are not doing enough to create an "inclusive and successful" environment (Schwitzer, Ancis, \& Griffin as cited in Kezar, 2000ª). Others (e.g., Golde \& Dore, 2001) argue that many students do not understand what doctoral study entails, how the process works, and how to navigate it effectively.

Recent studies indicate that the presence or absence of supportive human relationships with others, both faculty and fellow students, is important in determining the outcome of the doctoral experience (Hales, 1998; Schwarz, 1997). These features are often called human factors. More research is needed to understand the human factors associated with doctoral education, such as the impact of program culture, cohort support, the effect of mentoring, and faculty support. These human factors, also termed psychosocial factors, are the foremost rationale explaining why doctoral candidates fail to complete doctoral programs (Sigafus, 1998).

\section{Statement of the Problem}

Data related to degree completion indicate that forty to fifty percent of all doctoral students in this country fail to complete their programs (Dorn \& Papalewis, 1997; Lovitts, 1996). Research has suggested a wide array of reasons why doctoral candidates fail to complete doctoral programs: some become too busy with other endeavors; some find the situation financially burdening; and some decide the demands on themselves and their families are too great (Sigafus, 1998; Dorn \& Papalewis, 1997; NCES, 2001). 
However, more recent research indicates that human, or psychosocial, factors explain the majority of doctoral student attrition (Parent, 1999; Campbell, 1992). Tinto (1997) points to the negative effects of the transitions and discontinuities between the undergraduate and graduate experience. The level of faculty guidance and interaction creates a shift in program culture that often creates difficulty for the student. This relational strain between the student and instructor is one illustration of the human factors that exist within a doctoral program.

More current studies (e.g., Bair, 1999; Dorn \& Papalewis, 1997; Hales, 1998) on the doctoral experience suggest the greatest predictor of degree completion include such human factors as the faculty-student relationship, program culture or environment, and level of cohort/collegial support. The problem, however, is that most research related to doctoral degree completion or attrition focuses on student motivation, or other individual factors, as well as the demographic and academic variables that describe the students.

Research in the area of doctoral program completion is far from complete. Doctoral student attrition as an area of study is highly complex, largely because there is no systematic data collection processes within programs, graduate schools, college/university records offices, or national databases (Bair, 1999). Past assumptions on the importance of academic, demographic, and psychological factors cited in earlier research are being called into question (Bair, 1999; Parent, 1999). Further information is needed on why some students discontinue doctoral study and why others persist and graduate. As a result, there is insufficient information on which to base program decisions and policy that could contribute to higher completion rates in doctoral programs. More research is necessary to identify the human factors related to the attrition of doctoral students.

\section{Purpose of the Study}

The purpose of this study was to examine the factors - specifically the human factors of the faculty-student relationship, program culture or environment, and the level of cohort/collegial support — related to doctoral student attrition in education. In essence, this study sought to investigate the issues behind the consistently high attrition rates in doctoral programs of education in order to assist institutions of higher learning in creating programs to improve their rates of doctoral degree completion.

\section{Research Methodology}

A mixed-methods study was utilized for the research design. First, a causal-comparative design in the form of a survey questionnaire was employed. In causal-comparative, or ex post facto research, an attempt is made to determine either the cause or the consequence of a difference that previously existed between two or more groups of individuals (Fraenkel \& Wallen, 2000, p. 393). Causal-comparative research designs do not permit strong conclusions about cause-and-effect, but are useful for initial exploratory investigations (Gall, Gall, \& Borg, 2003). The current study examined two sets of variables and their relationships to doctoral program completion. These variable sets, or factors, included doctoral student perceptions of the human factors of the doctoral program experience and the individual student factors related to the experience.

Second, a qualitative and structured open-ended questioning approach was carried out for describing and interpreting the students' perceptions and experiences in the doctoral program. Structured, open-ended questions created responses scripted by the respondents, which helped to retain the accuracy of the response. Follow-up interviews with several of the doctoral student respondents were also conducted to further investigate the responses given to the open-ended items.

Using both quantitative and qualitative methodologies provided the researcher an opportunity for a deeper understanding of the complex human factors that influence doctoral student retention. As Erlandson (1993) notes, "Words enable the construction and communication of experience because they classify it" (p. 23). This research intended to build on the current knowledge and theory of doctoral student persistence and attrition, and contribute to the classification of knowledge about doctoral degree completion, to ultimately assist doctoral programs in universities in retaining their most precious resource, their students. 


\section{Research Design}

Using a survey instrument, doctoral students from two Texas regional university programs were asked to provide information concerning the following: (1) their demographics; (2) their status in the respective program; (3) their perceptions of individual factors or circumstances; and (4) their perception of the program culture, facultystudent relations, and cohort experience. The data were then analyzed in order to glean which factors are perceived as most significant in assisting doctoral degree completion.

Often, researchers have measures for several different variables and want to determine if a significant difference exists between them. In the present case, individual factors, program culture, faculty-student relationships, and cohort experience were all scale items with different resulting sample means, and tests of statistical significance were used to examine the differences between the sample mean values.

A one-sample $t$ test is used to compare a sample mean to a hypothesized test mean to determine the likelihood that the sample came from a particular population, given the conditions specified in the null hypothesis. Using the sampling distribution of all possible sample means, one is able to determine the probability of the sample mean belonging to a population associated with the specified test value.

For each of the individual items on the Likert-type scale and the open-ended items of the questionnaire instrument, a $t$ test could not be performed due to the level of measurement of the variables. When testing the null hypothesis that population means are equal, one computes the $t$ statistic. To test hypotheses about data that are counts, you compute the chi-square statistic and compare its value to the chi-square distribution to see the probability of obtaining the observed value if the null hypothesis is actually true (Norusis, 2003).

\section{Variables and Groups}

In the present study, it was not possible to categorize the sample doctoral students into two groups, those who were doctoral degree completers and those who were not. Out of the accessible population of 140 doctoral students, 21 students or $15 \%$ had not completed all of the requirements for the degree. However, the response rate for those 21 students not completing the program was quite low, resulting in a sample group of non-completers $\mathrm{N}=5$.

The test variables were selected based on previous findings in doctoral attrition studies. Based on the review of literature, the following variables appeared to be the most important to include in the evaluation: (1) the perceptions about the program culture; (2) the perceptions about faculty-student relationships; (3) the perceptions concerning the cohort experience; and (4) the perceptions of the individual student characteristics - motivation, fear of success, career goals, family demands, procrastination, and financial security. For the open-ended/qualitative portion of the questionnaire and interviews, the students were asked to report the things they perceived to assist them the most in the completion of the doctoral program. The responses to both the open-ended questions and the followup interviews were coded and categorized into themes, and then placed into one of the four broad categories of the test variables. 
An analysis model including the four factor areas can be represented as follows:

Figure 1: $\underline{\text { Model for Data Analysis with Four Factor Areas }}$

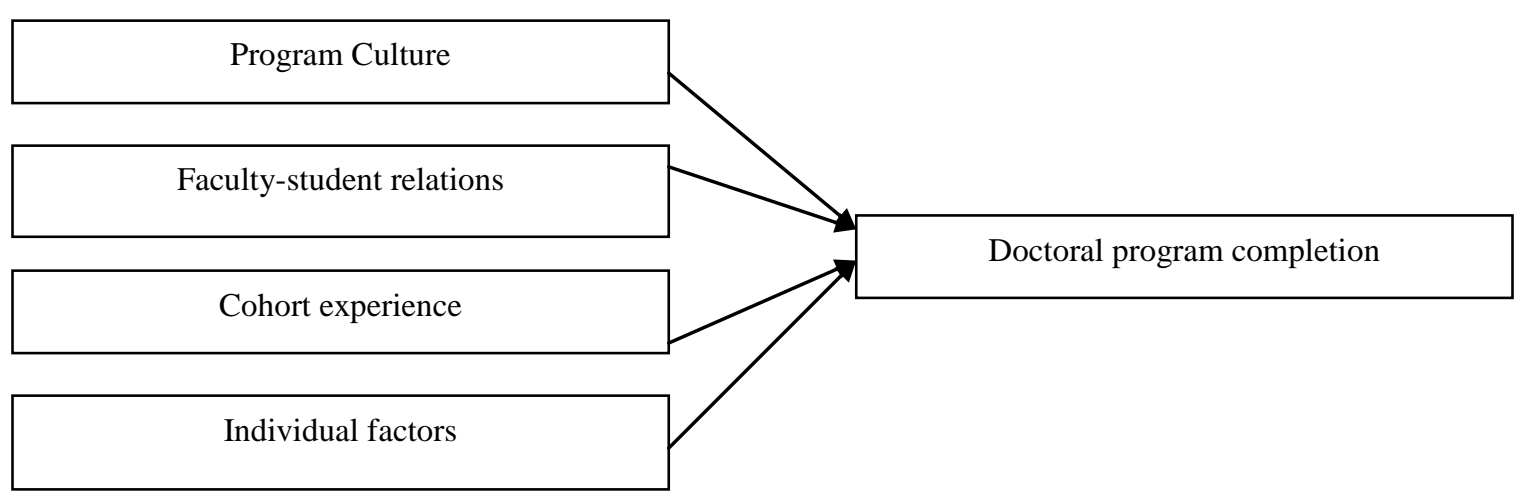

\section{Population and Sample}

The target population, or population of interest for the present study, included all educational leadership doctoral students in regional state universities. From this target, the accessible population included all doctoral students previously or currently enrolled in two regional universities that make up the Joint Doctoral Program in Educational Leadership at Texas A\&M University_Kingsville and Texas A\&M University - Corpus Christi. The pool of subjects, the 140 students from cohorts one through eight in the joint doctoral program, was obtained from the records maintained by the University programs.

\section{Data Analysis}

A one-sample $t$ test was conducted on the three "human factors" measurement scale scores. This test was conducted to evaluate whether their means were significantly different from the mean of the "individual factors" score. Table 1 contains these results.

Table 1

Mean Differences Between Average Responses for Human Factors Scale Items and the Individual Factors Mean Score, 24.98

\begin{tabular}{lccc}
\hline Measurement Scale & M & SD & t(56) \\
\hline Program Culture Factors & 28.47 & 3.71 & $7.11^{* * *}$ \\
Faculty-Student Relational Factors & 29.27 & 4.12 & $7.79^{* * *}$ \\
Cohort Factors & 27.32 & 5.01 & $3.52^{* * *}$ \\
\hline
\end{tabular}
$* * * \mathrm{p}<.001$.

The three sample means for each of the human factors measurement scales were significantly different from 24.98, the mean score for the individual factors measurement scale. The $t$ values ranged from $t(56)=3.52$ to $t(56)=7.79$. The resulting $p$-values were all less than .000 . The effect sizes, as evaluated by $d$, ranged from .47 to 1.04 , indicating medium to large effects. The results supported the conclusion that each of the human factor scales - program culture, faculty-student relationships, and cohort factors-had responses significantly greater than those of the individual factors scale. 
From the open-ended data, a one-sample chi-square test was conducted to assess whether respondents were equally likely to select each of the four types of factors in response to the second open-ended item on the questionnaire. The results of the test were significant, $\chi^{2}(3, N=56)=9.29, p=.026$. The proportion of respondents selecting relationships with faculty as assisting in program completion $(P=.39)$ was much greater than the hypothesized proportion of .25 , and the proportion selecting cohort structure $(P=.27)$ was also slightly greater than expected if the null hypothesis were true. Conversely, the proportions of students selecting individual factors and program cultural factors were less than the hypothesized proportions of .25 , with $P=.23$ and .11 , respectively.

On the whole, these results establish that doctoral students reported an overall significantly higher quantity of the human factors - faculty-student relationships and cohort/collegial support - than they did personal factors in explaining their own doctoral degree completion. Factors dealing specifically with the doctoral program culture were also not reported as often. In summary, the open-ended responses to the question "What most assisted you in completing the program?" indicated a significantly higher quantity of responses coded as faculty-student relational factors and cohort/collegial support factors.

\section{Summary of Findings}

After the individual questionnaire items were computed into the four scales that influence completion, the faculty-student relationships had the highest mean. This indicated that students placed a great deal of emphasis on how this factor contributed to their doctoral program completion. Individual factors had the smallest mean, with average responses to these items being closer to neutral. Program culture and cohort factors were second and third, respectively. Each of the mean scores for the three human factors-faculty-student relationships, program culture, and cohort structure-was significantly different (greater) than the mean score for the individual factors measurement scale.

What this signifies, is that when asked how they perceive different aspects of their doctoral program experience and what helped them to finish, doctoral students were more likely to strongly agree that human factors played a large role in their success. They gave more emphasis (strongly agree) to the responses dealing with the human factors, while they were more likely to respond neutrally (agree or neutral) to the questions dealing with individual issues. It appears as though students feel very strongly about the benefits of faculty-students relationships and program culture, and less so about individual factors that might affect program completion. The findings concerning the cohort experience appear to be mixed in both the quantitative and qualitative data from the study.

For the second open-ended item of the questionnaire instrument, respondents were not equally likely to respond with each of the four types of factors in answering the item "What most assisted you in completing the program?" Respondents reported faculty relational issues 39 percent of the time, and reported cohort support 27 percent of the time. Overall, 77 percent of the responses to the question asking for what most assisted students in completing the program were human factors. This is extremely convincing evidence of the great importance of the various human factors that play a significant role for students in the completion of the doctoral program. The additional data collected through both questionnaire items and follow-up interviews augment the finding that human factors play a significant role in the completion of doctoral studies. Scripted responses helped to clarify the complex issue of student perceptions on the doctoral student experience, and gave further support in the examination of the study's qualitative research question.

\section{Conclusions}

From the analysis of data, it can be shown that doctoral students perceive human factors to be of the utmost importance in doctoral program completion. In the review of the literature, the human factors of the program culture, faculty-student relationships, and cohort structure were found to be key factors in program success (Bair, 1999; Parent, 1999).

Overall, the perceptions of the doctoral students were consistent in that they perceived the human factorsfaculty-student relationships, program culture, and cohort support - to be the most significant in assisting in attaining the doctoral degree. Perhaps students realized that these are the types of factors that are in the realm of 
control for university programs, whereas individual factors are internal to the student. Researchers have argued that attrition has less to do with what the student brings to the university than with what happens to the student after she or he has been admitted, such as the program structure or culture (Lovitts, 1996). Either way, doctoral students report a significantly greater number of human factors than they do individual factors when explaining what most assisted them in their doctoral program experiences.

\section{References}

1. Bair, C.R. (1999). "Doctoral student attrition and persistence: A meta-synthesis". (Doctoral dissertation, Loyola University Chicago, 1999). UMI Microform 9917754.

2. Bishop, A.E. (1981). "The effect of fear of success on completion of the doctorate". Dissertation Abstracts International, 42(06).

3. Bowen, W. \& Rudenstine, N. (1992). In pursuit of the Ph.D.. Princeton, NJ: Princeton University Press.

4. Campbell, R.B. (1992). "A study of the completion and non-completion of the doctor of education degree in educational leadership at the University of Delaware". Dissertation Abstracts International, 53(06).

5. Donnelly, S.C. (1985). "An analysis of themes related to gender identity, social role, and achievement for women writing a doctoral dissertation". Dissertation Abstracts International, 46(12).

6. Dorn, S.M. \& Papalewis, R. (1997). Improving doctoral student retention. Paper presented at the Annual Meeting of the American Educational Research Association.

7. Erlandson, D.A. (1993). Doing naturalistic inquiry: A guide to methods. Newbury Park, CA: Sage.

8. Fraenkel, J.R. \& Wallen, N. (2000). How to design and evaluate research in education. New York: McGraw-Hill.

9. Gall, M.D., Gall, J.P. \& Borg, W.R. (2003). Educational Research: An Introduction, seventh edition. Upper Saddle River, NJ: Pearson Education, Inc.

10. Golde, C.M. \& Dore, T.M. (2001). At cross purposes: What the experiences of today's doctoral students reveal about doctoral education. ERIC Clearinghouse on Higher Education. Washington, DC: U.S. Department of Education.

11. Hales, K.S.E. (1998). "An analysis of factors relating to the attrition rate of doctoral students at the dissertation level at the School of Education and Human Development of the George Washington University". Dissertation Abstracts International, 44(04).

12. Hawley, P. (1993). Being bright is not enough: The unwritten rules of doctoral study. Springfield, IL: Charles C. Thomas Publisher.

13. Hoffer, T., Dugoni, B., Sanderson, A., Sederstrom, S., Ghadialy, R., \& Rocque, P. (2001). Doctorate Recipients from United States Universities: Summary Report 2000. Chicago: National Opinion Research Center.

14. Kezar, A.J. $\left(2000^{\mathrm{a}}\right)$. Higher education trends (1999-2000): Students. ERIC Clearinghouse on Higher Education. Washington, DC: U.S. Department of Education, Institute for Education Policy Studies.

15. Lemp, P.H. (1980). "Determinants of persistence in graduate education: The doctoral student". Dissertation Abstracts International, 41(05A).

16. Lovitts, B.E. (1996). Who is responsible for graduate student attrition: The individual or the institution? Toward an explanation of the high and persistent rate of attrition. (ERIC Document Reproduction Service No. ED 399 878).

17. Nagi, J.L. (1974). "Attrition factors in the Ed.D. Program in Educational Administration at State University of New York at Albany". Dissertation Abstracts International, 42(08).

18. National Center for Education Statistics. (2001). Digest of education statistics, 2001. Washington, DC: U.S. Department of Education, Office of Educational Research and Improvement.

19. Parent, E.R. (1999). What we know-and don't know-about factors determining the outcome of the doctoral experience. From http://weber.ucsd.edu/ eparent/part2/DA_text.html.

20. Schwarz, S. (1997). "Students' perceptions of the role of the dissertation chair in time to complete the doctoral dissertation". Dissertation Abstracts International, 58(07).

21. Sigafus, B. (1998). The creation of ABDs: A turning point in educational doctoral programs? Paper presented at the Annual Meeting of the American Educational Research Association.

22. Tinto, V. (1997). Contextualizing the study of graduate persistence. Paper presented at the Workshop on Graduate Student Attrition. Washington: National Science Foundation. 
23. Tluczek, J.L. (1995). "Obstacles and attitudes affecting graduate persistence in completing the doctoral dissertation". Dissertation Abstracts International, 56(05).

24. Wesson, L.H., Holman, S.O., Holman, D., \& Cox, D. (1996). Cohesion or collusion: Impact of a cohort structure on educational leadership doctoral students. Paper presented at the Annual Meeting of the American Educational Research Association (New York, NY, April 8-12, 1996).

Notes 